\title{
Other Healthcare Support Occupations
}

National Cancer Institute

\section{Source}

National Cancer Institute. Other Healthcare Support Occupations. NCI Thesaurus. Code C122545.

Healthcare support occupations not specifically identified elsewhere. 